\title{
Effects of sex and site on amino acid metabolism enzymes gene expression and activity in rat white adipose tissue
}

Sofía Arriarán, Silvia Agnelli, Xavier Remesar, José Antonio Fernández-López, Marià Alemany

Background and objectives. White adipose tissue (WAT) shows marked sex- and dietdependent differences. However, our metabolic knowledge of WAT, especially on amino acid metabolism, is considerably limited. In the present study, we compared the influence of sex on the amino acid metabolism profile of the four main WAT sites, focused on the paths related to ammonium handling and the urea cycle, as a way to estimate the extent of WAT implication on body amino-nitrogen metabolism.

Experimental design. Adult female and male rats were maintained, undisturbed, under standard conditions for one month. After killing them under isoflurane anesthesia. WAT sites were dissected and weighed. Subcutaneous, perigonadal, retroperitoneal and mesenteric WAT were analyzed for amino acid metabolism gene expression and enzyme activities.

Results. There was a considerable stability of the urea cycle activities and expressions, irrespective of sex, and with only limited influence of site. Urea cycle was more resilient to change than other site-specialized metabolic pathways. The control of WAT urea cycle was probably related to the provision of arginine/ citrulline, as deduced from the enzyme activity profiles. These data support a generalized role of WAT in overall amino-N handling. In contrast, sex markedly affected WAT ammonium-centered amino acid metabolism in a site-related way, with relatively higher emphasis in males' subcutaneous WAT.

Conclusions. We found that WAT has an active amino acid metabolism. Its gene expressions were lower than those of glucose-lipid interactions, but the differences were quantitatively less important than usually reported. The effects of sex on urea cycle enzymes expression and activity were limited, in contrast with the wider variations observed in other metabolic pathways. The results agree with a centralized control of urea cycle operation affecting the adipose organ as a whole. 
2 Effects of sex and site on amino acid metabolism enzymes gene 3 expression and activity in rat white adipose tissue

4 Sofía Arriarán ${ }^{1}$, Silvia Agnelli ${ }^{1}$, Xavier Remesar ${ }^{1,2,3}$, José Antonio Fernández-López ${ }^{1,2,3}$ and Marià 5 Alemany $1,2,3$

$6{ }^{1}$ Department of Nutrition and Food Science, University of Barcelona Faculty of Biology, Barcelona, Spain

$7 \quad$ Institute of Biomedicine, University of Barcelona, Barcelona, Spain

$8 \quad{ }^{3}$ CIBER-OBN Web of Research, Barcelona, Spain.

Corresponding Author: Dr. Marià Alemany; Department of Nutrition and Food Science, Faculty of Biology, University of Barcelona; Av. Diagonal, 643; 08028 Barcelona, Spain Tel. 34934034606; e-mail: 13 malemany@ub.edu

\section{ABSTRACT}

Background and objectives. White adipose tissue (WAT) shows marked sex- and diet-dependent differences. However, our metabolic knowledge of WAT, especially on amino acid metabolism, is considerably limited. In the present study, we compared the influence of sex on the amino acid metabolism profile of the four main WAT sites, focused on the paths related to ammonium handling and the urea cycle, as a way to estimate the extent of WAT implication on body amino-nitrogen metabolism.

Experimental design. Adult female and male rats were maintained, undisturbed, under standard conditions for one month. After killing them under isoflurane anesthesia. WAT sites were dissected and weighed. Subcutaneous, perigonadal, retroperitoneal and mesenteric WAT were analyzed for amino acid metabolism gene expression and enzyme activities.

Results. There was a considerable stability of the urea cycle activities and expressions, irrespective of sex, and with only limited influence of site. Urea cycle was more resilient to change than other site-specialized metabolic pathways. The control of WAT urea cycle was probably related to the provision of arginine/ citrulline, as deduced from the enzyme activity profiles. These data support a generalized role of WAT in overall amino-N handling. In contrast, sex markedly affected WAT ammonium-centered amino acid metabolism in a site-related way, with relatively higher emphasis in males' subcutaneous WAT.

Conclusions. We found that WAT has an active amino acid metabolism. Its gene expressions were lower than those of glucose-lipid interactions, but the differences were quantitatively less important than usually 
34 the wider variations observed in other metabolic pathways. The results agree with a centralized control of urea cycle operation affecting the adipose organ as a whole.

\section{INTRODUCTION}

The influence of sex on adipose tissue distribution and function, and its implication in metabolic syndrome has been known for a long time (Mayes \& Watson 2004). The protective effects of estrogen on adipose tissue activity (d'Eon et al. 2005), and limitation of its hypertrophic growth (Kumar et al. 2012) and inflammation (Stubbins et al. 2012) are key sex-related factors, which contribute to limit the disorders elicited by metabolic syndrome (Antonio et al. 2015). The distribution of fat in gynoid and android shapes of adult humans is a consequence of the close interrelationship of adipose tissue with androgens and estrogens (Kotani et al. 1994), modulated by their different response to glucocorticoids in the aftermath of a tissue defensive response against excess nutrient loads (Alemany 2012a).

There are clear differences between females and males in site distribution and metabolic responses (Demerath et al. 2007; Porter et al. 2004), but most studies on adipose tissue are limited to a single site or isolated cells, and are usually focused on the responses to inflammation (Revelo et al. 2014).

The extensive metabolic capability of white adipose tissue (WAT) show a remarkable uniformity in metabolic function and overall regulation (Carmean et al. 2014; Romero et al. 2014). As a consequence, the assumed main function of WAT (i.e. triacylglycerol storage as energy reserve) (Galic et al. 2010; Romacho et al. 2014) is been reconsidered because of the multiple functions of this unique disperse organ. (Eringa et al. 2012; Ferrante 2013; Giordano et al. 2014). However, the level of knowledge of WAT metabolism, other than the control of lipid synthesis and storage, remains remarkably insufficient, constituting a handicap for interpretation of its physiological role (Jensen 2007).

WAT contains a complete urea cycle, as shown in the present study, which is, probably implicated in the extra-splanchnic production of citrulline, a critical factor for muscle function (Ventura et al. 2013) and inter-organ 2-amino-N transport and utilization. However, WAT is also a massive producer of $3 \mathrm{C}$ fragments, such as lactate (Arriarán et al. 2015), but including alanine (Snell \& Duff 1977). WAT is also a net exporter of glutamine (Kowalski \& Watford 1994), and can use branched-chain amino acids for energy and lipogenesis (Herman et al. 2010). The large combined organ size, variety of known amino acid metabolic pathways and diverse physiological functions, hint at WAT as a potentially important site for peripheral amino acid metabolism. The information available is scant, we found only a couple of earlier studies (Kowalski et al. 1997; López-Soriano \& Alemany 1986); this is a serious limitation for a full understanding of whether amino acids should be also included in the well-established role of WAT in the management of energy, from glucose and lipids.

The little we know of WAT role in amino acid metabolism is further limited by our almost nil 
70 (Radcliffe \& Webster 1978); on the other hand, estrogens lower body weight (Bryzgalova et al. 2008), in spite of females (women) having -normally - a higher body fat percentage than males (men). Young women are more resistant to obesity than men (Meyer et al. 2011); however, after menopause, this estrogenic protection wanes (Cagnacci et al. 2007).

In this study, we intended to determine whether the gross differences in WAT distribution and its resilience to change had a robust biochemical basis. Thus, we analyzed whether the WAT urea cycle and related amino acid catabolic processes of rats showed sex-modulated differences. To obtain a wider picture we studied the four main (largest) WAT sites in parallel, and we included in the analysis (for comparison) a number of gene expressions involved in the control of WAT lipogenesis from glucose and lipolysis.

\section{MATERIALS AND METHODS}

\section{Experimental design and animal handling}

All animal handling procedures and the experimental setup were in accordance with the animal handling guidelines of the corresponding European and Catalan Authorities. The Committee on Animal Experimentation of the University of Barcelona specifically authorized the procedures used in the present study (DMAH-5483).

The experimental setup consisted on keeping two groups of undisturbed rats (female and male) under standard conditions for four weeks, in order to limit the influence of factors other than sex on the parameters analyzed.

Nine week old female and male Wistar rats (Harlan Laboratory Models, Sant Feliu de Codines, Spain) were used. The rats ( $\mathrm{N}=6$ per group) were housed in pairs (same sex) in solid-bottom cages with wood shards for bedding. They had free access to water and ate normal rat chow (type 2014, Harlan). The rats were kept in a controlled environment (lights on from $08: 00$ to $20: 00 ; 21.5-22.5^{\circ} \mathrm{C} ; 50-60 \%$ humidity) for one month.

The rats, without dietary manipulation, were killed, under isoflurane anesthesia, at the beginning of a light cycle (08:30 to 10:00), by aortic exsanguination, using dry-heparinized syringes; then, they were rapidly dissected, taking samples of WAT sites: mesenteric (ME), perigonadal (epididymal in males, periovaric in females, $P G$ ), retroperitoneal (RP) and subcutaneous (inguinal fat pads, SC). The samples were blotted and frozen with liquid nitrogen; after weighing, they were ground under liquid nitrogen and stored at $-80^{\circ} \mathrm{C}$ until processed. Later, the dissection of the rats continued, extracting the remaining WAT in ME, EP and RP sites; the rats were skinned, and the whole subcutaneous WAT was dissected. The weights of the recovered WAT were computed only to establish the total mass of each WAT site.

\section{Blood plasma parameters}

The blood obtained from the aorta was centrifuged to obtain plasma, which was frozen and kept at - 
106 was measured with another kit (ref. \#1001330; Spinreac, Sant Esteve de Bas, Spain). Amino acids were 107 analysed individually using an amino acid analyser (Pharmacia-LKB-Alpha-plus, Uppsala, Sweden) from 108 plasma samples deproteinized with acetone (Arola et al. 1977). Since the method used did not provide fair 109 analyses for glutamine (Gowda et al. 2015) and other amino acids (Trp, Cys, Asn), we decided to present 110 only the partial sum of the other amino acids as a single indicative value.

\section{Preparation of tissue homogenates}

112 Frozen tissue samples were homogenized, using a tissue disruptor (Ultraturrax IKA-T10, Ika Werke, 113 Staufen, Germany), in 5 volumes of chilled $70 \mathrm{mM}$ hepes buffer $\mathrm{pH} 7.4$ containing $1 \mathrm{mM}$ dithiothreitol 114 (Sigma, St Louis MO USA), $50 \mathrm{mM} \mathrm{KCl,} 1 \mathrm{~g} / \mathrm{L}$ Triton X-100 (Sigma) and $1 \mathrm{~g} / \mathrm{L}$ lipid-free bovine serum 115 albumin (Sigma). In homogenates to be used for carbamoyl-P synthase 2 estimation, the concentration of 116 Triton X-100 was halved to decrease foaming. The homogenates were centrifuged for $10 \mathrm{~min}$ at 5,000xg; 117 the floating fat layers and gross debris precipitates were discarded. The clean homogenates were kept on 118 ice, and used for enzymatic analyses within $2 \mathrm{~h}$ of their preparation.

119 Tissue protein content was estimated with the Lowry method (Lowry et al. 1951). After development 120 of color, fat droplet suspension-generated turbidity was eliminated with the addition of small amounts of 121 finely powdered solid $\mathrm{MgO}$ before reading the absorbance. In the measurements of homogenate protein 122 content, homogenization buffer (which contained albumin) was used as blank. Enzyme activities were 123 expressed in nkat/g protein.

124 Enzyme activity analyses

125 Carbamoyl-P synthase was estimated from the incorporation of ${ }^{14} \mathrm{C}$-bicarbonate (Perkin Elmer, Bad 126 Neuheim, Germany) into carbamoyl-P using a method previously described by us (Arriarán et al. 2012). No 127 significant carbamoyl-P synthase 1 activity was detected (and its gene was not expressed, either, in WAT). 128 Thus, only carbamoyl-P synthase 2 was measured.

129 All other enzyme activities (ornithine carbamoyl-transferase, arginino-succinate synthase, arginino130 succinate lyase and arginases 1 and 2) were estimated following recently developed methods, which are 131 presented in detail in a Supplementary annex both to justify their adequacy and to allow others to employ 132 a methodology developed for adipose tissue.

\section{Gene expression analysis}

134 Total tissue RNA was extracted from frozen tissue samples using the Tripure reagent (Roche Applied 135 Science, Indianapolis IN USA), and was quantified in a ND-100 spectrophotometer (Nanodrop

136 Technologies, Wilmington DE USA). These data were also used to determine the total RNA content of the 137 tissue (per $\mathrm{g}$ of tissue weight or $\mathrm{g}$ of protein) in order to establish comparisons between the quantitative 138 importance of gene expressions. RNA samples were reverse transcribed using the MMLV reverse 139 transcriptase (Promega, Madison, WI USA) system and oligo-dT primers.

140 Real-time PCR (RT-PCR) amplification was carried out using $10 \mu \mathrm{L}$ amplification mixtures containing 141 Power SYBR Green PCR Master Mix (Applied Biosystems, Foster City, CA USA), 4 ng of reverse- 
142 transcribed RNA and $150 \mathrm{nmol}$ of primers. Reactions were run on an ABI PRISM $7900 \mathrm{HT}$ detection system

143 (Applied Biosystems) using a fluorescent threshold manually set to 0.15 for all runs.

144 A semi-quantitative approach for the estimation of the concentration of specific gene mRNAs per unit

145 of tissue/ RNA or protein weight was used (Romero et al. 2007). Rplp0 was the charge control gene (Eagni

146 et al. 2013). We expressed the data primarily as the number of transcript copies per gram of protein in order

147 to obtain comparable data between the groups. The genes analyzed and a list of primers used is presented 148 in Table 1.

149 Figure 1 depicts a scheme of the relationships between the amino acid metabolism-related enzymes 150 which gene expressions have been analyzed in this study. This Figure also shows acronyms or 151 abbreviations of the names of the enzyme-genes used in Figures 2 and 3.

152 Sex differences in gene expression

153 The ample variability of cell volume, blood flow, innervation, size of fat deposits etc. of WAT poses 154 additional problems for comparison between different anatomical (i.e. site), physiological (i.e. sex, diet) and 155 pathological (i.e. obesity) situations (Caspar-Bauguil et al. 2005; Gil et al. 2011; Prunet-Marcassus et al. 156 2006). The variability of lipid reserves may convert in irrelevant comparisons based on weight; the use of 157 DNA or cell number is a better approach, but the multiple types of cells coexisting in WAT (and their widely 158 variable numbers) may also alter direct comparisons. We used as basic comparison the protein content, 159 largely because it has been the choice reference for enzyme activity and, by extension to gene expressions 160 and their possible interactions. However, probably a better way to measure changes in functional activity 161 may be the analysis of mRNA production. These changes do not parallel those of weight, protein content 162 or cell numbers, but are a fair index of the relative importance of translation of the genes involved with 163 respect to total protein synthesis. In fact, their use is complementary of the analysis of enzyme activity164 gene expression referred to protein weight, since it includes a new variable: metabolic transcendence for 165 the cell of the synthesis of the corresponding mRNAs. We calculated the relationships of gene expressions 166 to total tissue RNA (a crude approximation to mRNA) only to compare the specific effect of sex on a gene 167 expression in a given site. Any significant deviation on the proportion of a gene expression with respect to 168 the whole RNA mass may imply a differential modulation of this expression. We included these additional 169 data to provide further insight into the ways and means of manifestation of sex-related differences.

170 Statistics

171 Student's $t$ test (unpaired) and two-way ANOVA comparisons between groups (using the post-hoc

172 Tuckey test), correlations and curve fitting (including $V_{i}$ estimations) were analyzed with the Prism 5 173 program (GraphPad Software, San Diego CA USA). Data were presented as mean \pm sem, and a limit of 174 significance of $\mathrm{P}<0.05$ was used throughout.

175

176 RESULTS

177 Basic parameters 
Table 2 shows the body and main adipose tissue sites weights of undisturbed female and male animals. When aged 13 weeks, female rats weighed about $62 \%$ of their male counterparts. The males accumulated more fat than females, both in individual sites and as a whole. However, the sum of the four sites analyzed showed almost identical proportions vs. body weight, c. 8\%. However, there were sexrelated individual site differences in relative size expressed as percentage of body weight. There were also differences in total protein and RNA proportions (per $\mathrm{g}$ of fresh tissue) between the different sites, but there were no global effects attributable to the variable "sex".

The main plasma parameters studied are presented in Table 3. Plasma glucose levels were higher in males than in females. However, these data were influenced by isoflurane anesthesia (Zardooz et al. 2010), and are presented only as a general indication of normalcy. No differences were observed for lactate and total cholesterol. Triacylglycerol levels were significantly higher in females (albeit in the limit of statistical significance). Both plasma urea and the partial sum of amino acids were also higher in female than in male rats.

Urea cycle enzymes

Figure 2 depicts urea-cycle enzyme activities and the expression of their corresponding genes in four main WAT sites of male and female rats. In both cases, activity and gene expression, the data were presented per $\mathrm{g}$ of tissue protein. The data are displayed on a log scale to allow a visual comparison of the site patterns of enzyme activities and expressions. The data used in this representation are also tabulated in numeric form in the Supplemental Tables 1 and 2. There was a considerable coincidence in the patterns of enzyme activity distribution (and male-female similarities) in enzyme activities for all four sites. This pattern was not paralleled by that of the corresponding gene expression data, which also showed considerable uniformity in their patterns across the WAT sites. The statistical analysis of the data in Figure 2 showed significant differences for "site" for all enzyme expressions except for arginino-succinate synthase. The site-related differences in enzyme activities, however, were limited to arginino-succinate lyase and carbamoyl-P synthase.

Subcutaneous WAT showed more differences between sexes than other locations, affecting carbamoyl-P synthase 2 (both activity and gene expression) and arginino-succinate lyase (only activity). Arginino-succinate synthase activity showed differences between females and males in mesenteric WAT, and its higher expression was observed in periovaric WAT.

\section{Other amino acid metabolism-related gene expressions}

Figure 3 shows the gene expressions of the non-urea cycle enzymes presented in Figure 1, as well as differentiated arginases 1 and 2, which were combined in Figure 2. The data are depicted also on a log scale to facilitate pattern comparison; the corresponding numerical results are shown in Supplemental

211 Table 3.

212 In all sites, the expression of e-NOS was, at least one order of magnitude higher than arginase; 213 subcutaneous WAT being an exception: despite showing a similar pattern of expressions, the levels of 
214 mRNA per $g$ of tissue protein were higher for most genes, in subcutaneous WAT, than in the other three

215 sites. There was a generalized predominance of glutamine synthetase expression over that of glutaminase.

216 The glycine cleavage system (specifically the $\mathrm{H}$ protein of the complex) and AMP deaminase showed also

217 a robust expression, at levels comparable to those of alanine transaminases. The two branched-chain

218 amino acid transaminases were also within this range, but the expression of the form 2 was much higher.

219 The statistical comparisons of the data in Figure 3 present limited effects for sex; overall only nitric

220 oxide synthase, alanine transaminase 2 and glutaminase showed significant overall differences between

221 female and male rats. Paired sex-related differences were concentrated in subcutaneous WAT, with higher

222 male values in the expression of nitric oxide synthase, glutamine synthase (but female-predominant

223 glutaminase), AMP deaminase and alanine transaminase 1. No sex-related differences were found in the

224 other sites, except higher male values in alanine transaminase 2 of perigonadal WAT. The differences

225 between sites, however, were more marked, affecting all genes studied except $\mathrm{N}$-acetyl-glutamate

226 synthase (low expression) and arginase 2, which was expressed only in subcutaneous WAT.

227 Gene expressions of proteins involved in WAT acyl-glycerol metabolism

228 Figure 4 presents the gene expressions of the key transporter and enzymes that regulate the 229 lipogenic process from glucose to acetyl-CoA and from that metabolite to acyl-CoA, including the three

230 most important WAT lipases. The data are presented in a log scale and the numerical data are shown in

231 Supplemental Table 4. In spite of a considerable uniformity in the patterns for all four sites, there were 232 marked differences in the extent of gene expression. In general, subcutaneous WAT values were higher, 233 than those of the other sites. Again, overall (for mesenteric, retroperitoneal and perigonadal WAT), female 234 expression values tended to be higher than those of the males for genes coding proteins favoring glucose 235 incorporation (GLUT4, hexokinase), generation of NADPH (glucose-6P dehydrogenase, malic enzyme), 236 and lipogenesis (citrate: ATP lyase, and acetyl-CoA carboxylase). Regulation of pyruvate dehydrogenase

237 by its inhibiting kinases was higher in males, suggesting a lower mitochondrial availability of acetyl-CoA. In 238 males, mitochondrial handling of fatty acids (carnitine palmitoleoyl-transferases, acyl-CoA 239 dehydrogenases) and lipolysis (except adipose triacylglycerol lipase) showed higher relative expressions 240 than in females.

241 Subcutaneous WAT showed higher expression values for males in pyruvate dehydrogenase kinase 242 4, palmitoleoyl.carnitine acyl-transferase (liver), acyl-CoA dehydrogenase and both lipoprotein and adipose 243 triacylglycerol lipases. In mesenteric WAT, the only significant difference was for higher malic enzyme 244 expression in females. In retroperitoneal WAT, female expression values were higher for malic enzyme, 245 citrate: ATP lyase and acetyl-CoA carboxylase. Again, in perigonadal WAT, female expression values were 246 higher for glucose-6P dehydrogenase. The overall differences for "site" were significant for all genes 247 investigated except for GLUT4, malic enzyme, citrate: ATP lyase and fatty acid synthase.

248 Comparison of female and male gene expression 
Table 4 summarizes the sex-related differences in gene expression. The data are presented in two

250

251

252

253

254

255

256

257

258

259

260

261

262

263

264

265

266

267

268

269

270

271

272

273

274

275

276

277

278

279

280

281

282

283

284

cooperative forms: expression per unit of protein and per unit of RNA weight in the tissue. The corresponding numerical data for RNA data and complete statistical analysis are shown on Supplemental Table 5. Table 4 shows only the cases where female-male differences were significant, and the genes are divided in four sections. In the first, corresponding to urea-cycle enzymes, only carbamoyl-P synthase 2 of subcutaneous WAT showed higher female than male values. No other differences were seen. There was a high degree of superimposition between the data obtained from protein and RNA; but the number of enzymes with statistically significant between sexes was higher in most WAT sites when the data of reference was RNA than when related to tissue protein.

Other amino acid metabolism data showed a relative predominance of higher relative expressions in males, especially affecting the transaminases. The sites with more differences were subcutaneous and retroperitoneal WAT. In contrast, lipogenesis was more highly expressed in females, with minimal effects on subcutaneous and highest in retroperitoneal WAT. Male predominance was observed again on pyruvate dehydrogenase kinases' expressions, which increase marks a lower rate of production of acetyl-CoA as substrate for acyl-CoA synthesis. Finally, in the analysis of lipolytic and lipid oxidation-related genes, the male higher values were the norm, especially in subcutaneous and retroperitoneal WAT.

\section{DISCUSSION}

The results presented support a wide extension of amino acid metabolism in different sites of WAT, with enzyme activities and expressions following similar patterns in all four sites studied. In addition to urea cycle, AMP-deaminase (Arola et al. 1981a), glutamine synthetase (Arola et al. 1981b), glutamate dehydrogenase (Arola et al. 1979) and nitric oxide synthase (Pilon et al. 2000), we found that WAT expresses the glycine cleavage system (at least the $\mathrm{H}$ protein), so far not described.

The metabolic capabilities of WAT with respect to amino acid metabolism are probably more extensive than usually assumed (Alemany 2012b), largely because it is unknown, with scant literature references to WAT amino acid metabolism (Herman et al. 2010; Kowalski et al. 1997; Lackey et al. 2013; López-Soriano \& Alemany 1986). The range of expressions observed for amino acid metabolism-related enzymes in the four WAT sites studied (Figures 2 and 3) was mostly in the 5-500 fmol/g protein. In comparison, the expressions (Figure 4) for lipogenesis, the (assumed) main metabolic function of WAT, and other lipid metabolism-related expressions were in the range of $10-1000 \mathrm{fmol} / \mathrm{g}$ protein. Thus, the differences between lipogenesis and amino acid metabolism-related gene expressions were not as extensive as expected from the known massive mobilization/ deposition of triacylglycerols in adipocytes, compared with the relatively low level of cell proteins (Salans \& Dougherty 1971) (and cytoplasm) of WAT. This is compounded by the lack of sufficient data on WAT amino acid metabolism above indicated. The relatively elevated amino acid metabolism enzyme levels and gene expressions found hint at a potential relative importance of WAT on body amino acid metabolism. 
The considerable uniformity of WAT urea cycle-enzyme activities and expressions, and their marked independence of sex can be interpreted essentially in two ways: a) as playing a minimal metabolic role: i.e., a residual, secondary or specialized pathway. Or, alternatively, b), it can be assumed to be a consequence of a well-established and robust homeostatic maintenance of its function. That is, a role critical enough not to be sensibly influenced by external regulatory factors such as sex hormones. The first possibility may seem the more obvious, but it is insufficient to counter a number of critical arguments: First of all, the unexpectedly high level of enzyme expressions and activities. Individual urea cycle enzymes are present in many tissues, (Emmanuel 1980; Nishibe 1974; Rath et al. 2014). However, the mere existence of a complete urea cycle in a peripheral organ outside the splanchnic bed has not been previously described, as far as we know. A full operative urea cycle has been described only for liver (Emmanuel 1980). The key question is whether this cycle is functional or not. Due to its methodological difficulties, it should be studied using other (i.e. tracer) techniques. However, the relatively high enzyme activities and gene expressions observed, and the fact that all urea cycle and related ammonium metabolism enzymes are present suggest that this distribution has a clear functional purpose. This is, consequently, a situation different from that of tissues, which contain only part of the cycle to serve other metabolic purposes. The lack of sex-related differences in WAT sites of urea cycle compared with lipogenic processes, as shown in Figures 2-4 and the remarkable uniformity in pattern distribution between WAT sites also support the functionality of WAT urea cycle.

The varying ratios of activity/ expression suggest a main post-translational control, extended to all sites. The high ornithine carbamoyl-transferase vs. arginino-succinate synthase activities suggest a probable implication in the peripheral (and critical) synthesis of citrulline (Yu et al. 1996), which may complement its conversion by the kidney (Borsook \& Dubnoff 1941). WAT participates in substrate cycles, including alanine synthesis (Snell \& Duff 1977) and glutamine release (Kowalski \& Watford 1994) in which amino acids are implicated. This analysis is further complicated by the quantitative importance of both activity and gene expressions compared with those of lipogenesis, the mainstay of WAT metabolism. Our understanding of these differences is complicated by the overall large size of the adipose organ (Romero et al. 2014), even taking into account the metabolically inert mass of fat. Taken together, these arguments support a significant role of WAT in amino acid metabolism.

Our data suggest, in any case, a clear site-sex interaction (Jaubert et al. 1995; Lemonnier 1972) that brings up differences in the expression of several amino acid metabolism-related genes other than urea

315 cycle, which remains uncannily undisturbed and globally uniform. In males, subcutaneous WAT shows

316 higher expressions for genes related to transfer of acyl-CoA to the mitochondria and its oxidation than 317 females; this is consistent with the possibility of using fatty acids as energy substrate. The higher male 318 inhibition of pyruvate dehydrogenase, by kinases, generalized to most sites, reinforces this trend. On the 319 other side, the expression of WAT lipogenic enzyme genes (especially when expressed with respect to total 320 RNA) was higher in females than in males. In contrast, lipases practically did not show differences. The 321 different female-male specific metabolic predominance in WAT sites prove that the limited changes in urea 
322 cycle, compared with lipogenesis, could not be solely a consequence of overall lack of effects of sex on

323 WAT; but it is, instead, a specific characteristic of WAT urea cycle as compared to other metabolic 324 pathways.

325 The higher lipogenic (and lower lipolytic) gene expressions of female WAT is counterintuitive when

326

327

328

329

330

331

332

333

334

335

336

337

338

339

340

341

342

343

344

345

346

347

348

349

350

351

352

353

354

355

356

357 we think of the higher WAT mass of adult male rats (Romero et al. 2014). Probably, the lower male gene expressions found here mirror a less active metabolism, in conjunction with the intestine and liver. The visceral fat accumulation in adult men (Bosch et al. 2015) as compared with women is correlated with insulin resistance (Pascot et al. 2000) and other metabolic syndrome-related pathologies (Watanabe \& Tochikubo 2003). The discordances in sex-related control of metabolism and fat deposition between humans and rats are a critical caveat against generalization to humans of what is found using animal models, in spite of shared mechanisms and trends.

In addition to the human-rodent question, the main limitation of this study is the lack of previous data with which establish comparisons, made even more difficult by our scarce knowledge of amino acid metabolism. The extensive and interconnected net of pathways needs to be investigated. The most critical handicap, however, is the lack of a critical mass of scientists and of actualized methodology: specific protein measurement reagents (antibodies), and/or methods (and products) for the estimation of enzyme activities and metabolites of amino acid metabolism. Consequently, the data we present here should be taken as just an initial foray into a highly promising field of study.

An additional question may help explain the differences between sites (Lemonnier 1972; Rydén et al. 2014), and the influence of sex (and sex hormones), the differences in cell populations of different WAT sites. A factor that affects the mean adipocyte size (also influenced by obesity (Garaulet et al. 2006)) and the presence of other types of cells, in different proportions, such as macrophages (Králová Lesná et al. 2015), stem cells (Ogura et al. 2014) and other stromal components (Maumus et al. 2011).

Notwithstanding these caveats, the data gathered all point to a few preliminary conclusions, which could not be yet fully proven with the data we presented, largely because no other results are available for comparison or independent confirmation. The potential for lipid handling of WAT sites was strongly modulated by sex, being considerably dependent on the site studied. This part of the study, devised to provide a background comparison for amino acid metabolism showed more extensive differences than expected, and needs to be studied more specifically and deeply before sufficiently based conclusions could be extracted.

There was a considerable stability of the urea cycle activities and expressions, irrespective of sex, and with only limited influence of site. Which we interpret as this cycle operation being more general than the specialized site metabolic peculiarities, with robust control of WAT urea cycle, probably related to a possible role as provider of arginine/ citrulline (Beliveau Carey et al. 1993). The resilience to change of urea cycle, in the context of a tissue characterized by its plastic adaptability, supports a generalized, probably essential, role in overall amino $\mathrm{N}$ handling. 
In contrast, sex affected deeply WAT ammonium-centered amino $\mathrm{N}$ metabolism in a site-related fashion, with relatively higher levels of activity in males and in female subcutaneous WAT. The data on amino acid catabolism fit also with a role of mesenteric WAT as gatekeeper of the portal system, the hypothesis advanced for WAT glucose disposal (Arriarán et al. 2015) can be easily translated to the management of possible transient excesses of dietary amino acids.

In sum, WAT seems to play significant role in overall amino acid metabolism, including a functional urea cycle, which is not affected by sex. Contrary to lipid/ glucose-related pathways, the data presented point to a centralized control of urea cycle operation affecting the adipose organ as a whole.

\section{REFERENCES}

Alemany M. 2012a. Do the interactions between glucocorticoids and sex hormones regulate the development of the metabolic syndrome? Frontiers in Endocrinology 3.

Alemany M. 2012b. The problem of nitrogen disposal in the obese. Nutrition Research Reviews 25:18-28.

Antonio L, Wu FCW, O'Neill TW, Pye SR, Carter EL, Finn JD, Rutter MK, Laurent MR, Huhtaniemi IT, Han TS, Lean MEJ, Keevil BG, Pendleton N, Rastrelli G, Forti G, Bartfai G, Casanueva FF, Kula K, Punab M, Giwercman A, Claessens F, Decallonne B, and Vanderschueren D. 2015. Associations between sex steroids and the development of metabolic syndrome: A longitudinal study in European men. Journal of Clinical Endocrinology and Metabolism 100:1396-1404.

Arola L, Herrera E, and Alemany M. 1977. A new method for deproteinization of small samples of blood plasma for amino acid determination. Analytical Biochemistry 82:236-239.

Arola L, Palou A, Remesar X, and Alemany M. 1979. NADH and NADPH dependent glutamate dehydrogenase activities in the organs of the rat. IRCS Medical Science 7:364-364.

Arola L, Palou A, Remesar X, and Alemany M. 1981a. Adenylate deaminase activity in the rat - effect of 24 hours of fasting. Hormone and Metabolic Research 13:264-266.

Arola L, Palou A, Remesar X, and Alemany M. 1981b. Glutamine-synthetase activity in the organs of fed and 24-hours fasted rats. Hormone and Metabolic Research 13:199-202.

Arriarán S, Agnelli S, Fernández-López JA, Remesar X, and Alemany M. 2012. A radiochemical method for carbamoyl-phosphate synthetase-I: Application to rats fed a hyperproteic diet. Journal of Enzyme Research 3:29-33.

Arriarán S, Agnelli S, Sabater D, Remesar X, Fernández-López JA, and Alemany M. 2015. Evidences of basal lactate production in the main white adipose tissue sites of rats. Effects of sex and a cafeteria diet. PloS One 10: e0119572.

Beliveau Carey G, Cheung CW, Cohen NS, Brusilow S, and Raijman L. 1993. Regulation of urea and citrulline synthesis under physiological conditions. Biochemical Journal 292:241-247.

Borsook H, and Dubnoff JW. 1941. The conversion of citrulline to arginine in kidney. Journal of Biological Chemistry 141:717-738.

Bosch TA, Steinberger J, Sinaiko AR, Moran A, Jacobs DR, Kelly AS, and Dengel DR. 2015. Identification of sex-specific thresholds for accumulation of visceral adipose tissue in adults. Obesity 23:375382.

Bryzgalova G, Lundholm L, Portwood N, Gustafsson JA, Khan A, Efendic S, and Dahlman-Wright K. 2008. Mechanisms of antidiabetogenic and body weight-lowering effects of estrogen in high-fat diet-fed mice. American Journal of Physiology 295:E904-E912. 
400

401

402

403

404

405

406

407

408

409

410

411

412

413

414

415

416

417

418

419

420

421

422

423

424

425

426

427

428

429

430

431

432

433

434

435

436

437

438

439

440

441

442

Cagnacci A, Zanin R, Cannoletta M, Generali M, Caretto S, and Volpe A. 2007. Menopause, estrogens, progestins, or their combination on body weight and anthropornetric measures. Fertility and Sterility 88:1603-1608.

Carmean CM, Cohen RN, and Brady MJ. 2014. Systemic regulation of adipose metabolism. Biochimica et Biophysica Acta 1842:424-430.

Caspar-Bauguil S, Cousin B, Galinier A, Segafredo C, Nibbelink M, Andre A, Casteilla L, and Pénicaud L. 2005. Adipose tissues as an ancestral immune organ: Site-specific change in obesity. FEBS Letters 579:3487-3492.

d'Eon TM, Souza SC, Aronovitz M, Obin MS, Fried SK, and Greenberg AS. 2005. Estrogen regulation of adiposity and fuel partitioning. Evidence of genomic and non-genomic regulation of lipogenic and oxidative pathways. Journal of Biological Chemistry 280:35983-35991.

Demerath EW, Sun SS, Rogers N, Lee MY, Reed D, Choh AC, Couch W, Czerwinski SA, Chumlea WC, Siervogel RM, and Towne B. 2007. Anatomical patterning of visceral adipose tissue: race, sex, and age variation. Obesity 15:2984-2993.

Eagni E, Viganò M, Rebulla P, Giordano R, and Lazzari L. 2013. What is beyond qRT-PCR study on mesencymal stem cell differentiation properties: how to choose the most reliable housekeeping genes. Journal od Cellular and Molecular Medicine 17:168-180.

Emmanuel B. 1980. Urea cycle enzymes in tissues (liver, rumen epithelium, heart, kidney, lung and splee of sheep (Ovis aries). Comparative Biochemistry and Physiology 65B:693.697.

Eringa EC, Bakker W, and van Hinsbergh VWM. 2012. Paracrine regulation of vascular tone, inflammation and insulin sensitivity by perivascular adipose tissue. Vascular Pharmacology 56:204-209.

Ferrante AW. 2013. The immune cells in adipose tissue. Diabetes Obesity and Metabolism 15:34-38.

Galic S, Oakhill JS, and Steinberg GR. 2010. Adipose tissue as an endocrine organ. Molecular and Cellular Endocrinology 316:129-139.

Garaulet M, Hernandez-Morante JJ, Lujan J, Tebar FJ, and Zamora S. 2006. Relationship between fat cell size and number and fatty acid composition in adipose tissue from different fat depots in overweight/obese humans. International Journal of Obesity 30:899-905.

Gil A, Olza J, Gil-Campos M, Gomez-Llorente C, and Aguilera CM. 2011. Is adipose tissue metabolically different at different sites? International Journal of Pediatric Obesity 6:13-20.

Giordano A, Smorlesi A, Frontini A, Barbatelli G, and Cinti S. 2014. White, brown and pink adipocytes: the extraordinary plasticity of the adipose organ. European Journal of Endocrinology 170:R159-R171.

Gowda GAN, Gowda YN, and Raftery D. 2015. Massive glutamine cyclization to pyroglutamic acid in human serum discovered using NMR spectroscopy. Analytical Chemistry 87:3800-3805.

Griggs RC, Kingston W, Jozefowicz RF, Herr BE, Forbes G, and Halliday D. 1989. Effect of testosterone on muscle mass and muscle protein synthesis. Journal of Applied Physiology 66:498-503.

Herman MA, She PX, Peroni OD, Lynch CJ, and Kahn BB. 2010. Adipose tissue branched chain amino acid (BCAA) metabolism modulates circulating BCAA levels. Journal of Biological Chemistry 285:11348-11356.

Jaubert AM, Pecquery R, Dieudonné MN, and Giudicelli Y. 1995. Estrogen binding sites in hamster white adipose tissue: Sex- and site-related variations; Modulation by testosterone. General and Comparative Endocrinology 2:179-187.

Jensen MD. 2007. Adipose tissue metabolism - An aspect we should not neglect? Hormone and Metabolic Research 39:722-725. 
443

444

445

446

447

448

449

450

451

452

453

454

455

456

457

458

459

460

461

462

463

464

465

466

467

468

469

470

471

472

473

474

475

476

477

478

479

480

481

482

483

484

485

Kotani K, Tokunaga K, Fujioka S, Kobatake T, Keno Y, Yoshida S, Shimomura I, Tarui S, and Matsuzawa Y. 1994. Sexual dimorphism of age-related-changes in whole-body fat distribution in the obese. International Journal of Obesity 18:207-212.

Kowalski TJ, and Watford M. 1994. Production of glutamine and utilization of glutamate by rat subcutaneous adipose tissue in vivo. American Journal of Physiology 266:E151-E154.

Kowalski TJ, Wu GY, and Watford M. 1997. Rat adipose tissue amino acid metabolism in vivo as assessed by microdialysis and arteriovenous techniques. American Journal of Physiology 273:E613-E622.

Králová Lesná I, Poledne R, Fronek J, Králová A, Sekerková A, Thieme F, and Pitha J. 2015. Macrophage subsets in the adipose tissue could be modified by sex and the reproductive age of women. Atherosclerosis 241:255-258.

Kumar A, Ruan M, Clifton K, Syed F, Khosla S, and Oursler MJ. 2012. TGF-b mediates suppression of adipogenesis by estradiol through connective tissue growth factor induction. Endocrinology 153:254-263.

Lackey DE, Lynch CJ, Olson KC, Mostaedi R, Ali M, Smith WH, Karpe F, Humphreys S, Bedinger DH, Dunn TN, Thomas AP, Oort PJ, Kieffer DA, Amin R, Bettaieb A, Haj FG, Permana P, Anthony TG, and Adams SH. 2013. Regulation of adipose branched-chain amino acid catabolism enzyme expression and cross-adipose amino acid flux in human obesity. American Journal of Physiology 304:E1175-E1187.

Lemonnier D. 1972. Effect of age, sex, and site on the cellularity of the adipose tissue in mice and rats rendered obese by a high-fat diet. Journal of Clinical Investigation 51:2907-2915.

López-Soriano FJ, and Alemany M. 1986. Amino acid metabolism enzyme activities in rat white adipose tissue. Archives Internationales de Physiologie et Biochimie 94:121-125.

Lowry OH, Rosebrough RW, Farr AL, and Randall RJ. 1951. Protein measurement with the Folin phenol reagent. Journal of Biological Chemistry 193:265-275.

Maumus M, Peyrafitte JA, d'Angelo R, Fournier-Wirth C, Bouloumié A, Casteilla L, Sengenès C, and Bourin P. 2011. Native human adipose stromal cells: localization, morphology and phenotype. International Journal of Obesity 35:1141-1153.

Mayes JS, and Watson GH. 2004. Direct effects of sex steroid hormones on adipose tissues and obesity. Obesity Reviews 5:197-216.

Meyer MR, Clegg DJ, Prossnitz ER, and Barton M. 2011. Obesity, insulin resistance and diabetes: sex differences and role of oestrogen receptors. Acta Physiologica 203:259-269.

Nishibe H. 1974. Urea cycle enzymes in human erythrocytes. Clinica Chimica Acta 50:305-310.

Ogura F, Wakao S, Kuroda Y, Tsuchiyama K, Bagheri M, Heneidi S, Chazenbalk G, Aiba S, and Dezawa M. 2014. Human adipose tissue possesses a unique population of pluripotent stem cells with nontumorigenic and low telomerase activities: potential implications in regenerative medicine. Stem Cells and Development 23:717-728.

Pascot A, Després JP, Lemieux I, Bergeron J, Nadeau A, Prid'homme D, Tremblay A, and Lemieux S. 2000. Contribution of visceral obesity to the deterioration of the metabolic risk profile in men with impaired glucose tolerance. Diabetologia 43:1126-1135.

Pilon G, Penfornis P, and Marette A. 2000. Nitric oxide production by adipocytes: A role in the pathogenesis of insulin resistance? Hormone and Metabolic Research 32:480-484.

Porter MH, Fine JB, Cutchins AG, Bai YH, and DiGirolamo M. 2004. Sexual dimorphism in the response of adipose mass and cellularity to graded caloric restriction. Obesity Research 12:131-140. 
486

487

488

489

490

491

492

493

494

495

496

497

498

499

500

501

502

503

504

505

506

507

508

509

510

511

512

513

514

515

516

517

518

519

520

521

522

523

524

Prunet-Marcassus B, Cousin B, Caton D, André M, Pénicaud L, and Casteilla L. 2006. From heterogeneity to plasticity in adipose tissues: Site-specific differences. Experimental Cell Research 312:727-736.

Radcliffe JD, and Webster AJF. 1978. Sex, body composition and regulation of food intake during growth in the Zucker rat. British Journal of Nutrition 39:483-492.

Rath M, Muller I, Kropf P, Closs El, and Munder M. 2014. Metabolism via arginase or nitric oxide synthase: two competing arginine pathways in macrophages. Frontiers in Immunology 5:532.

Revelo X, Luck H, Winer S, and Winer D. 2014. Morphological and inflammatory changes in visceral adipose tissue during obesity. Endocrine Pathology 25:93-101.

Romacho T, Elsen M, Rohrborn D, and Eckel J. 2014. Adipose tissue and its role in organ crosstalk. Acta Physiologica 210:733-753.

Romero MM, Grasa MM, Esteve M, Fernández-López JA, and Alemany M. 2007. Semiquantitative RT PCR measurement of gene expression in rat tissues including a correction for varying cell size and number. Nutrition and Metabolism 4:26.

Romero MM, Roy S, Pouillot K, Feito M, Esteve M, Grasa MM, Fernández-López JA, Alemany M, and Remesar X. 2014. Treatment of rats with a self-selected hyperlipidic diet, increases the lipid content of the main adipose tissue sites in a proportion similar to that of the lipids in the rest of organs and tissues. PloS One 9:e90995.

Rydén M, Andersson DP, Bergström IB, and Arner P. 2014. Adipose tissue and metabolic alterations: Regional differences in fat cell size and number matter, but differently: A cross-sectional study. Journal of Clinical Endocrinology and Metabolism 99:E1870-E1876.

Salans LB, and Dougherty JW. 1971. The effect of insulin upon glucose metabolism by adipose cells of different size. Influence of cell lipid and protein content, age, and nutritional state. Journal of Clinical Investigation 50:1399-1410.

Snell K, and Duff DA. 1977. Alanine release by rat adipose tissue in vitro. Biochemical and Biophysical Research Communications 77:925-931.

Stubbins RE, Najjar K, Holcomb VB, Hong J, and Núñez NP. 2012. Oestrogen alters adipocyte biology and protects female mice from adipocyte inflammation and insulin resistance. Diabetes Obesity and Metabolism 14:58-66.

Ventura G, Noirez P, Breuille D, Godin JP, Pinaud S, Cleroux M, Choisy C, le Plenier S, Bastic V, Neveux N, Cynober L, and Moinard C. 2013. Effect of citrulline on muscle functions during moderate dietary restriction in healthy adult rats. Amino Acids 45:1123-1131.

Watanabe J, and Tochikubo O. 2003. Relationship between visceral fat accumulation and hypertension in obese men. Clinical and Experimental Hypertension 25:199-208.

Yu YM, Burke JF, Tompkins RG, Martin R, and Young VR. 1996. Quantitative aspects of interorgan relationships among arginine and citrulline metabolism. American Journal of Physiology 271:E1098-E1109.

Zardooz H, Rostamkhani F, Zaringhalam J, and Shahrivar FF. 2010. Plasma corticosterone, insulin and glucose changes induced by brief exposure to isoflurane, diethyl ether and $\mathrm{CO}_{2}$ in male rats. Physiological Research 59:973-978. 
Table $\mathbf{1}$ (on next page)

Primer sequences used in the analysis of WAT gene expressions 


\begin{tabular}{|c|c|c|c|c|c|c|}
\hline & protein & gene & EC & primer sequence $5^{\prime}>3^{\prime}$ & primer sequence $3^{\prime}>5^{\prime}$ & $\mathrm{bp}$ \\
\hline CPS2 & glutamine-dependent carbamoyl-phosphate synthase & Cad & 6.3.5.5 & AGTTGGAGGAGGAGGCTGAG & ATTGATGGACAGGTGCTGGT & 90 \\
\hline OTC & ornithine carbamoyl transferase & Otc & 2.1.3.3 & CTTGGGCGTGAATGAAAGTC & ATTGGGATGGTTGCTTCCT & 126 \\
\hline ASS & arginino-succinate synthase & Ass1 & 6.3.4.5 & CAAAGATGGCACTACCCACA & GTTCTCCACGATGTCAATGC & 100 \\
\hline ASL & arginino-succinate lyase & Asl & 4.3.2.1 & CCGACCTTGCCTACTACCTG & GAGAGCCACCCCTTTCATCT & 104 \\
\hline ARG1 & arginase-1 & $\operatorname{Arg} 1$ & 3.5.3.1 & GCAGAGACCCAGAAGAATGG & GTGAGCATCCACCCAAATG & 126 \\
\hline ARG2 & arginase-2 & $\operatorname{Arg} 2$ & 3.5.3.1 & GCAGCCTCTTTCCTTTCTCA & CCACATCTCGTAAGCCAATG & 122 \\
\hline NAGS & $\mathrm{N}$-acetyl-glutamate synthase & Nags & 2.3 .1 .1 & GCAGCCCACCAAAATCAT & CAGGTTCACATTGCTCAGGA & 82 \\
\hline eNOS & nitric oxide synthase, endothelial & Nos3 & 1.14 .13 .39 & CAAGTCCTCACCGCCTTTT & GACATCACCGCAGACAAACA & 138 \\
\hline GS & glutamine synthetase & Glul & 6.3 .1 .2 & AACCCTCACGCCAGCATA & CTGCGATGTTTTCCTCTCG & 148 \\
\hline Gase & glutaminase kidney isoform, mitochondrial & G/s & 3.5 .1 .2 & CCGAAGGTTTGCTCTGTCA & AGGGCTGTTCTGGAGTCGTA & 63 \\
\hline GDH1 & glutamate dehydrogenase 1 , mitochondrial & Glud1 & 1.4.1.3 & GGACAGAATATCGGGTGCAT & TCAGGTCCAATCCCAGGTTA & 122 \\
\hline GCS & glycine cleavage system $\mathrm{H}$ protein, mitochondrial & Gcsh & -- & AAGCACGAATGGGTAACAGC & TCCAAAGCACCAAACTCCTC & 146 \\
\hline AMPD & AMP deaminase 2 & Ampd2 & 3.5.4.6 & CGGCTTCTCTCACAAGGTG & CGGATGTCGTTACCCTCAG & 78 \\
\hline AlaT1 & alanine aminotransferase 1 & Gpt & 2.6.1.2 & GTATTCCACGCAGCAGGAG & CACATAGCCACCACGAAACC & 85 \\
\hline AlaT2 & alanine aminotransferase 2 & Gpt2 & 2.6.1.2 & CATTCCCTCGGATTCTCATC & GCCTTCTCGCTGTCCAAA & 146 \\
\hline BCT1 & branched-chain-amino-acid aminotransferase, cytosolic & Bcat1 & 2.6 .1 .42 & TGCCCAGTTGCCAGTATTC & CAGTGTCCATTCGCTCTTGA & 138 \\
\hline BCT2 & branched-chain-amino-acid aminotransferase, mitochondrial & Bcat2 & 2.6 .1 .42 & AGTCTTCGGCTCAGGCACT & ATGGTAGGAATGTGGAGTTGCT & 84 \\
\hline GLUT4 & solute carrier family 2 (facilitated glucose transporter), member 4 & Glut4 & -- & CACAATGAACCAGGGGATGG & CTTGATGACGGTGGCTCTGC & 127 \\
\hline HK & hexokinase-2 & Hk2 & 2.7.1.1 & ATTCACCACGGCAACCACAT & GGACAAAGGGATTCAAGGCATC & 113 \\
\hline G6PDH & glucose-6-phosphate 1- dehydrogenase & G6pdx & 1.1.1.49 & GACTGTGGGCAAGCTCCTCAA & GCTAGTGTGGCTATGGGCAGGT & 77 \\
\hline ME & NADP-dependent malic enzyme & Me1 & 1.1.1.40 & TTCCTACGTGTTCCCTGGAG & GGCCTTCTTGCAGGTGTTTA & 131 \\
\hline PDHK2 & pyruvate dehydrogenase kinase 2, mitochondrial & Pdk2 & 2.7 .11 .2 & TCACTСТСССТСССАТСАА & CGCCTCGGTCACTCATTT & 75 \\
\hline PDHK4 & pyruvate dehydrogenase [acetyl transferring] kinase 4 , mitochondrial & Pdk4 & 2.7 .11 .2 & GTCAGGCTATGGGACAGATGC & TTGGGATACACCAGTCATCAGC & 137 \\
\hline CATPL & ATP citrate lyase & Acly & 2.3 .3 .8 & GACCAGAAGGGCGTGACCAT & GTTGTCCAGCATCCCACCAGT & 96 \\
\hline ACoAC & acetyl-CoA carboxylase 1 & Acaca & 6.4 .1 .2 & AGGAAGATGGTGTCCGCTCTG & GGGGAGATGTGCTGGGTCAT & 145 \\
\hline FAS & fatty acid synthase & Fasn & 2.3 .1 .85 & CTTGGGTGCCGATTACAACC & GCCCTCCCGTACACTCACTC & 163 \\
\hline PCATI & carnitine palmitoyltransferase 1 , liver isoform & Cpt1a & 2.3 .1 .21 & CCGCTCATGGTCAACAGCA & CAGCAGTATGGCGTGGATGG & 105 \\
\hline PCATm & carnitine palmitoyltransferase 2, mitochondrial & Cpt2 & 2.3 .1 .21 & TGCTTGACGGATGTGGTTCC & GTGCTGGAGGTGGCTTTGGT & 152 \\
\hline ACADH & long-chain acyl-CoA dehydrogenase, mitochondrial & Acadl & 1.3 .8 .8 & ATGCCAAAAGGTCTGGGAGT & TCGACCAAAAAGAGGCTAATG & 148 \\
\hline ATL & adipose triacylglycerol lipase & Atgl & 3.1 .1 .3 & CGGTGGATGAAGGAGCAGACA & TGGCACAGACGGCAGAGACT & 138 \\
\hline HSL & hormone-sensitive lipase & Lipe & 3.1 .1 .79 & CCCATAAGACCCCATTGCCTG & CTGCCTCAGACACACTCCTG & 94 \\
\hline \multirow[t]{2}{*}{ LPL } & lipoprotein lipase & $L p l$ & 3.1 .1 .34 & GAAGGGGCTTGGAGATGTGG & TGCCTTGCTGGGGTTTTCTT & 103 \\
\hline & $60 S$ acidic ribosomal protein 0 (housekeeping gene) & Rplp0 & -- & GAGCCAGCGAAGCCACACT & GATCAGCCCGAAGGAGAAGG & 62 \\
\hline
\end{tabular}




\section{Table 2 (on next page)}

Body and WAT site weight and composition of adult male and female Wistar rats.

The data correspond to the mean \pm sem of 6 different animals. Statistical significance of the differences between groups was established with a 2-way anova; post-hoc Tuckey test: an asterisk * represents $\mathrm{P}<0.05$ differences between sex groups. Comparison of differences between the sums of sites was done using the Student's $t$ test. \% BW = percentage of body weight. 


\begin{tabular}{|c|c|c|c|c|c|c|}
\hline parameter & unit & site & male & female & p site & $p \operatorname{sex}$ \\
\hline body weight & $g$ & -- & $373 \pm 6.1$ & $232 \pm 8.2$ & -- & $<0.0001$ \\
\hline \multirow{10}{*}{ WAT weight } & \multirow{5}{*}{$g$} & SC & $12.2 \pm 0.20^{*}$ & $7.02 \pm 0.25$ & \multirow{4}{*}{$<0.0001$} & \multirow{4}{*}{$<0.0001$} \\
\hline & & $\mathrm{ME}$ & $4.94 \pm 0.49^{*}$ & $3.92 \pm 0.33$ & & \\
\hline & & PE & $7.34 \pm 0.64^{*}$ & $4.83 \pm 0.39$ & & \\
\hline & & $\mathrm{RE}$ & $6.29 \pm 0.79^{*}$ & $2.79 \pm 0.35$ & & \\
\hline & & $\Sigma$ WAT & $30.8 \pm 1.7$ & $18.6 \pm 0.93$ & -- & $<0.0001$ \\
\hline & \multirow{5}{*}{$\%$ BW } & SC & $3.28 \pm 0.05$ & $3.04 \pm 0.11$ & \multirow{4}{*}{$<0.0001$} & \multirow{4}{*}{ NS } \\
\hline & & ME & $1.33 \pm 0.18$ & $1.69 \pm 0.13$ & & \\
\hline & & PE & $1.97 \pm 0.13$ & $2.10 \pm 0.21$ & & \\
\hline & & RE & $1.69 \pm 0.22$ & $1.22 \pm 0.17$ & & \\
\hline & & $\Sigma$ WAT & $8.26 \pm 0.47$ & $8.05 \pm 0.52$ & -- & NS \\
\hline \multirow{4}{*}{ protein } & \multirow{4}{*}{$\mathrm{mg} / \mathrm{g}$} & SC & $63.1 \pm 11.6$ & $51.8 \pm 3.3$ & \multirow{4}{*}{$<0.0001$} & \multirow{4}{*}{ NS } \\
\hline & & ME & $74.2 \pm 7.4$ & $84.2 \pm 2.6$ & & \\
\hline & & PE & $44.3 \pm 1.6$ & $54.4 \pm 2.4$ & & \\
\hline & & $\mathrm{RE}$ & $65.1 \pm 6.3$ & $62.9 \pm 4.7$ & & \\
\hline \multirow{4}{*}{ RNA } & \multirow{4}{*}{$\mu \mathrm{g} / \mathrm{g}$} & SC & $248 \pm 51$ & $219 \pm 19$ & \multirow{4}{*}{$<0.0001$} & \multirow{4}{*}{ NS } \\
\hline & & ME & $880 \pm 84$ & $793 \pm 88$ & & \\
\hline & & PE & $94.3 \pm 6.0$ & $119 \pm 10$ & & \\
\hline & & $\mathrm{RE}$ & $48.8 \pm 4.1$ & $78.4 \pm 4.1$ & & \\
\hline
\end{tabular}

2 


\section{Table 3(on next page)}

Main energy plasma parameters of adult female and male Wistar rats

The data correspond to the mean \pm sem of 6 different animals. Statistical significance of the differences between groups was established with the unpaired Student's t test. *This value does not include GIn, Asn, Trp and Cys. 


\begin{tabular}{|l|c|c|c|c|}
\hline parameter & units & male & female & P sex \\
\hline glucose & $\mathrm{mM}$ & $10.20 \pm 0.42$ & $8.64 \pm 0.34$ & 0.0169 \\
\hline lactate & $\mathrm{mM}$ & $3.10 \pm 0.29$ & $3.78 \pm 0.24$ & $\mathrm{NS}$ \\
\hline total cholesterol & $\mathrm{mM}$ & $1.97 \pm 0.07$ & $1.98 \pm 0.16$ & $\mathrm{NS}$ \\
\hline triacylglycerols & $\mathrm{mM}$ & $1.50 \pm 0.06$ & $1.69 \pm 0.06$ & 0.0491 \\
\hline urea & $\mathrm{mM}$ & $3.90 \pm 0.17$ & $5.13 \pm 0.25$ & 0.0029 \\
\hline amino acids* $^{*}$ & $\mathrm{mM}$ & $3.34 \pm 0.08$ & $3.96 \pm 0.18$ & 0.0104 \\
\hline
\end{tabular}

1 


\section{Table 4 (on next page)}

Comparison of male-female specific expression of genes in different WAT sites with respect to tissue total protein or RNA

The data are the mean \pm sem of 6 animals per group, and are expressed as fmol of the corresponding gene mRNA per $\mathrm{g}$ of protein or $\mathrm{mg}$ of total RNA. The complete numerical data Table for RNA is presented in Supplemental Table 5. Only significant differences are shown. $M>F$ represents that male data were significantly higher than those of females; $F>M$ represented that female data were significantly higher than those of males. Analysis of significance was done using 1- and 2-way anovas (the latter for combined sites). The data in regular font correspond to significant values in the expression of $\mathrm{fmol} / \mathrm{mg}$ RNA, those in italics correspond to the data which were significant only when expressed as fmol/g protein. The data in bold correspond to differences statistically significant both when referred to tissue protein and RNA. 


\begin{tabular}{|c|c|c|c|c|c|}
\hline \multirow{2}{*}{ parameter } & \multicolumn{4}{|c|}{ WAT site } & \multirow{2}{*}{ all sites $P$} \\
\hline & SC & ME & $P G$ & $\mathrm{RP}$ & \\
\hline \multicolumn{6}{|c|}{ urea cycle enzymes } \\
\hline carbamoyl-P synthase 2 & $\mathbf{F}>\mathbf{M}$ & - & - & - & $F>M$ \\
\hline ornithine carbamoyl-transferase & - & - & - & - & - \\
\hline argininosuccinate synthase & - & - & - & - & - \\
\hline argininosuccinate lyase & - & - & - & - & - \\
\hline arginase 1 & - & - & - & - & - \\
\hline \multicolumn{6}{|c|}{ other enzymes of amino acid metabolism } \\
\hline $\mathrm{N}$-acetyl-glutamate synthase & $M>F$ & - & - & - & - \\
\hline glutamate dehydrogenase 1 & - & - & - & - & - \\
\hline glutamine synthetase & $M>F$ & - & - & - & $\mathrm{M}>\mathrm{F}$ \\
\hline glutaminase & $F>M$ & $\mathrm{~F}>\mathrm{M}$ & - & - & $F>M$ \\
\hline AMP deaminase & $M>F$ & - & - & - & $M>F$ \\
\hline glycine cleavage system & - & - & $F>M$ & - & - \\
\hline alanine transaminase 1 & $M>F$ & - & - & $M>F$ & $M>F$ \\
\hline alanine transaminase 2 & $M>F$ & - & $M>F$ & $M>F$ & $M>F$ \\
\hline branched-chain amino acid transaminase 1 & - & - & $M>F$ & $M>F$ & $M>F$ \\
\hline branched-chain amino acid transaminase 2 & - & - & - & - & - \\
\hline endothelial nitric oxide synthase & $M>F$ & - & - & $M>F$ & $M>F$ \\
\hline \multicolumn{6}{|c|}{ enzymes (and transporters) related with lipogenesis from glucose } \\
\hline glucose transporter 4 & - & - & - & $\mathrm{F}>\mathrm{M}$ & $\mathbf{F}>\mathbf{M}$ \\
\hline hexokinase 2 & - & - & $\mathrm{F}>\mathrm{M}$ & $\mathrm{F}>\mathrm{M}$ & $\mathrm{F}>\mathrm{M}$ \\
\hline glucose-6P dehydrogenase & - & $\mathrm{F}>\mathrm{M}$ & $\mathbf{F}>\mathbf{M}$ & $\mathrm{F}>\mathrm{M}$ & $\mathbf{F}>\mathbf{M}$ \\
\hline malic enzyme & - & $\mathrm{F}>\mathrm{M}$ & $\mathrm{F}>\mathrm{M}$ & $\mathbf{F}>\mathbf{M}$ & $\mathbf{F}>\mathbf{M}$ \\
\hline pyruvate dehydrogenase kinase 2 & $M>F$ & - & - & $M>F$ & $M>F$ \\
\hline pyruvate dehydrogenase kinase 4 & $M>F$ & - & - & $M>F$ & $M>F$ \\
\hline citrate: ATP lyase & - & $\mathrm{F}>\mathrm{M}$ & - & $\mathbf{F}>\mathbf{M}$ & $\mathbf{F}>\mathbf{M}$ \\
\hline acetyl-CoA carboxylase & $\mathrm{F}>\mathrm{M}$ & $\mathrm{F}>\mathrm{M}$ & - & $\mathbf{F}>\mathbf{M}$ & $\mathbf{F}>\mathbf{M}$ \\
\hline fatty acid synthase & - & $\mathrm{F}>\mathrm{M}$ & $\mathrm{F}>\mathrm{M}$ & $\mathrm{F}>\mathrm{M}$ & $\mathrm{F}>\mathrm{M}$ \\
\hline \multicolumn{6}{|c|}{ enzymes (and transporters) related with lipolysis and fatty acid oxidation } \\
\hline carnitine palmitoleoyl transferase (liver) & $M>F$ & - & $M>F$ & $M>F$ & $M>F$ \\
\hline carnitine palmitoleoyl transferase (muscle) & - & - & - & - & $M>F$ \\
\hline long-chain acyl-CoA dehydrogenase & $M>F$ & $\mathrm{~F}>\mathrm{M}$ & - & - & $M>F$ \\
\hline
\end{tabular}




\begin{tabular}{|c|c|c|c|c|c|}
\hline adipose tissue triacylglycerol lipase & $M>F$ & - & - & $M>F$ & $M>F$ \\
\hline hormone-sensitive lipase & - & - & - & - & $M>F$ \\
\hline lipoprotein lipase & $M>F$ & - & - & $M>F$ & - \\
\hline
\end{tabular}




\section{1}

Scheme of the core of amino acid metabolism in WAT: urea cycle and ammonium handling

The abbreviations (marked in red) of the enzymes involved in the pathways depicted are the same described in Table 1 and throughout this study

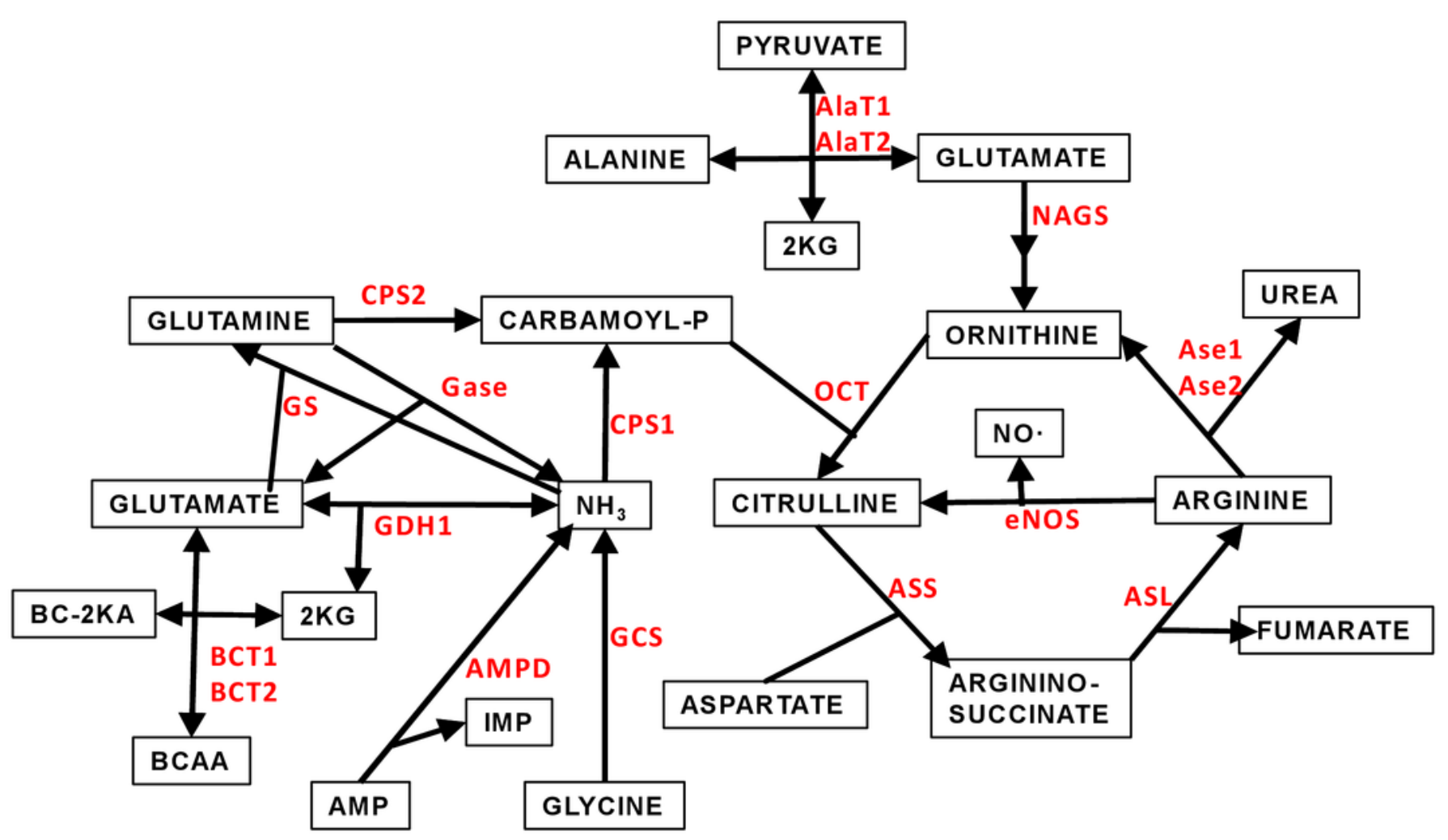




\section{2}

Urea cycle enzyme activities and expressions of their coding genes in four WAT sites of female and male rats

All data are the mean \pm sem of 6 animals, and are presented in a log scale. The numerical data are shown in Supplemental Tables 1 and 2. Left panels: enzyme activities, red columns correspond to males and orange to female rats. Right panels: gene expressions, blue columns represent the males, and green the females. CPS2 = carbamoyI-P synthase 2; OTC = ornithine carbamoyl-transferase; ASS = arginino-succinate synthase; ASL = argininosuccinate lyase; $A R G=$ arginase. Statistical analysis (2-way anova) of the differences between groups. Activity: There were no significant differences for "sex"; CPS2 and ASL showed $\mathrm{P}<0.0001$ for "site". Expression: only CPS2 showed a significant $(\mathrm{P}=0.0002)$ for "sex": There were significant differences for "site" in CPS2 and ASL ( $P<0.0001)$, OTC $(P=0.0081)$, ARG1+2 $(P<0.0001) ;$ ASS showed no significant differences. The application of post-hoc Tuckey test between male/female pairs are shown in the Figure as red stars. 

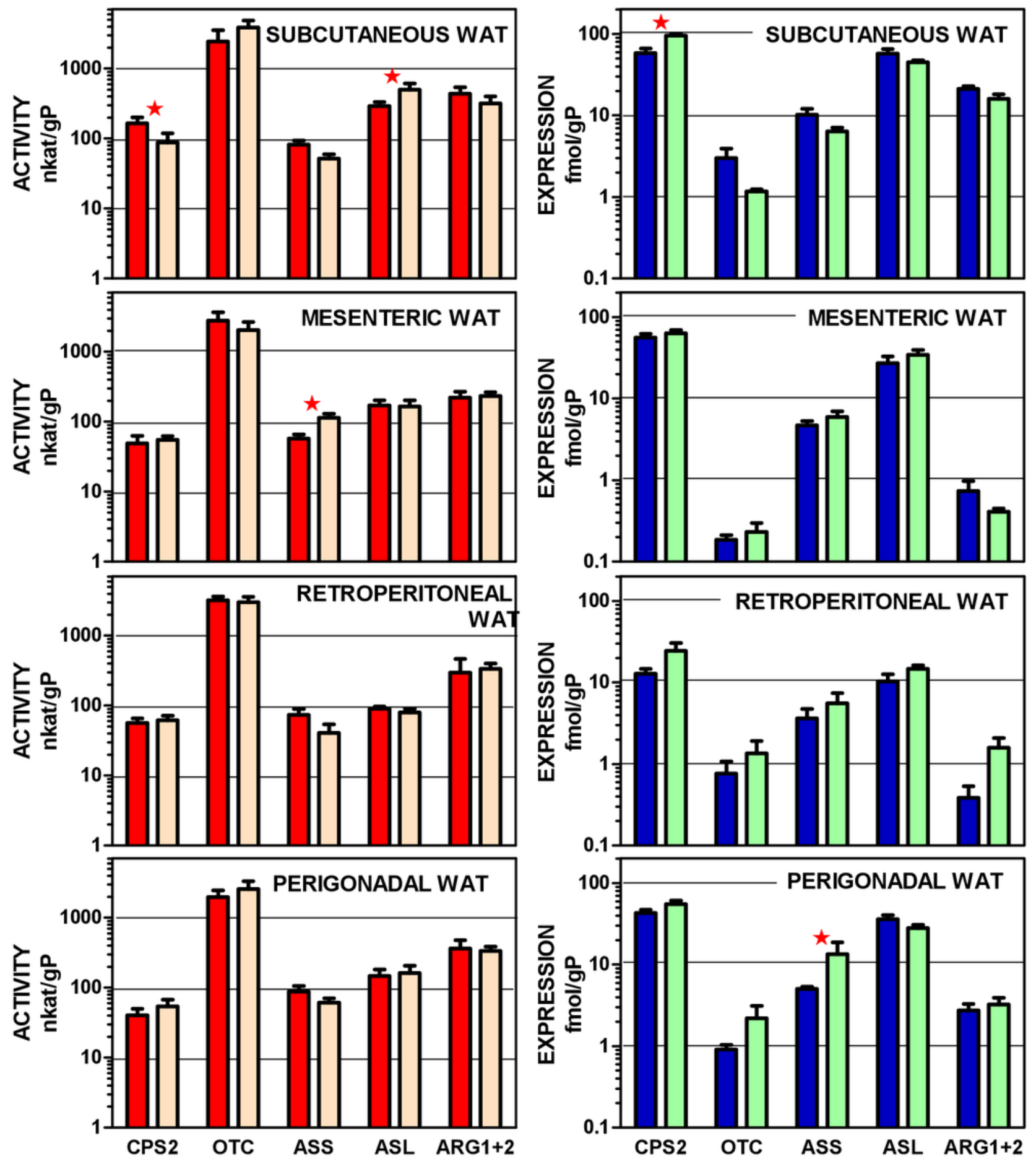
3

Expression of genes coding for enzymes of amino acid metabolism in WAT sites of male and female rats

All data are the mean \pm sem of 6 animals, and are presented in a log scale. The numerical data are shown in Supplemental Table 3. Blue columns represent the males, and green the females. NAGS $=\mathrm{N}$-acetyl glutamate synthase; Ase $1=$ arginase 1 ; Ase $2=$ Arginase 2; eNOS = endothelial nitric oxide synthase; GS = glutamine synthetase; Gase = glutaminase; GDH1 = glutamate dehydrogenase (NADPH); AMPD = AMP deaminase; AlaT1 = alanine transaminase 1; AlaT2 = alanine transaminase $2 ; \mathrm{BCT1}=$ branched-chain amino acid transaminase $1 ; \mathrm{BCT} 2=$ branched-chain amino acid transaminase 2 . Statistical analysis (2way anova) of the differences between groups. The variable "sex" showed global differences for Gase $(P<0.0001)$, eNOS $(P=0.0014)$ and AlaT2 $(P=0.0018)$. The variable "site" showed significant differences for all genes ( $P<0.0001$ for eNOS, Gase, GDH1, AMPD, BCT1 and AlaT2; $P=0.0005$ for Ase1; $P=0.0014$ for GS; $P=0.0023$ for AlaT1, $P=0.024$ for $B C T 2$, and $\mathrm{P}=0.039$ for GCS) except N-acetyl-glutamate synthase. The application of post-hoc Tuckey test between male/female pairs are shown in the Figure as red stars between the corresponding columns. 

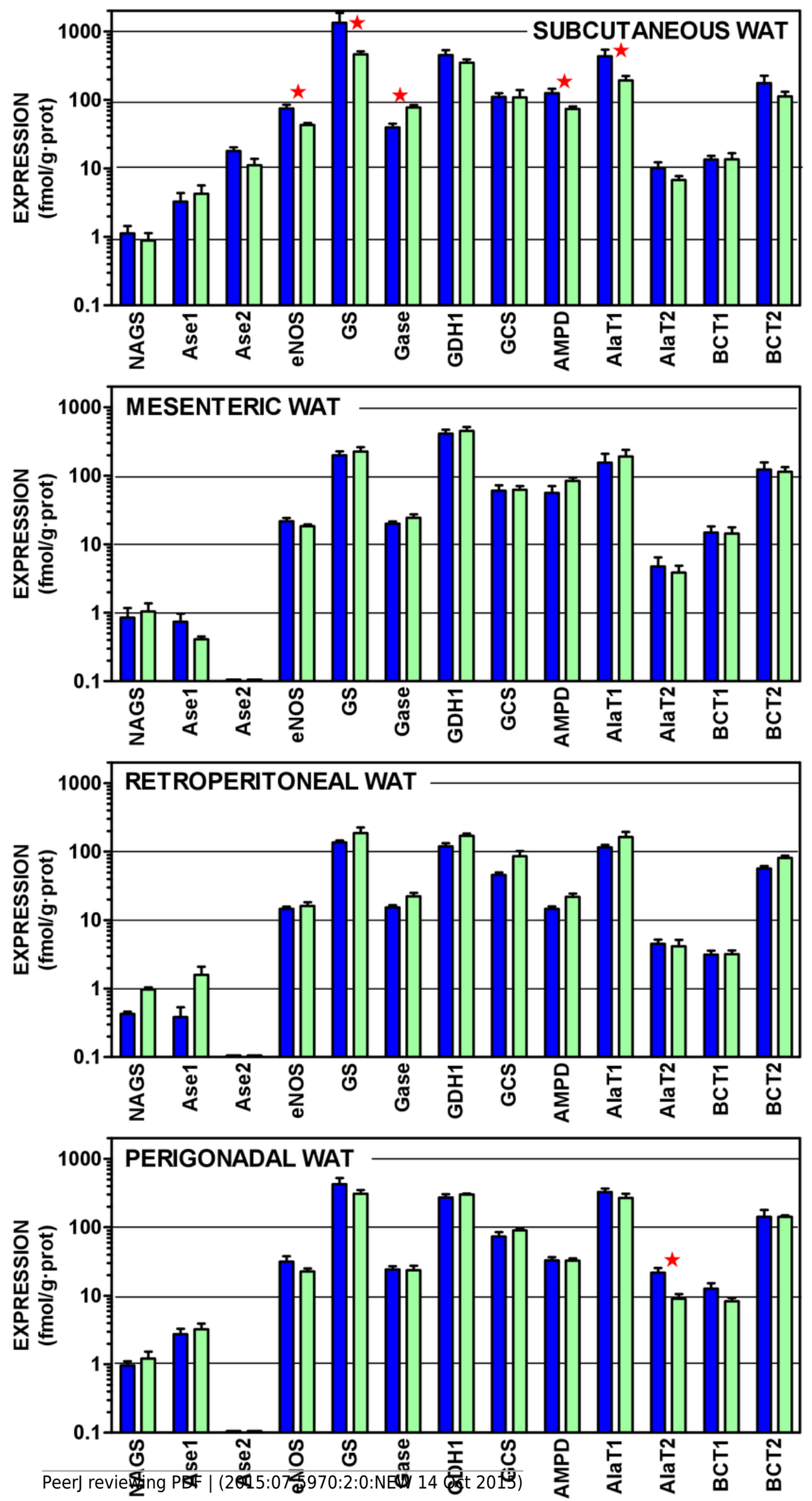


\section{4}

Expression of genes coding for transporter and enzymes related to lipogenesis from glucose and catabolism of lipid stores in WAT sites of male and female rats

All data are the mean \pm sem of 6 animals, and are presented in a log scale. The numerical data are shown in Supplemental Table 4. Blue columns represent the males, and green the females. GLUT4 = glucose transpoirter 4; HK = hexokinase; G6PDH = glucose-6P dehydrogenase; $\mathrm{ME}=$ malic enzyme; PDHK2 = pyruvate dehydrohenase kinase 2; PDHK4 = pyruvate dehydrohenase kinase 4; CATPL = citrate: ATP lyase; $\mathrm{AcCoAC}=$ acetyl-CoA carboxylase; FAS = fatty acid synthase; PCATI = palmitoleoyl-carnitine acyl-transferase (liver); PCATm = palmitoleoyl-carnitine acyl-transferase (muscle); AcADH = acyl-CoA dehydrogenase; $A T L=$ adipose triacylglycerol lipase; $H S L=$ hormone-sensitive lipase; $L P L=$ lipoprotein lipase. Statistical analysis (2-way anova) of the differences between groups. The variable "sex" showed global differences for HK ( $P=0.0009)$, AcCoAC $(P=0.0035)$, GLUT4 $(P=0.0040), C A T P L(P=0.010), G 6 P D H(P=0.020)$, PHDK4 $(P=0.020), M E(P=0.024)$ and ATL $(P=0.026)$. The variable "site" showed significant differences for HSL, ATL and LPL $(P<0.0001)$, PCATI $(P=0.0004), G 6 P D H(P=0.0005)$, PDHK2 $(P=0.0013)$. PDHK4 $(P=0.0016)$, ACADH (0.0022), HK ( $P=0.0057), P C A T m(P=0.015)$ and AcCoAC $(P=0.0384)$. The application of post-hoc Tuckey test between male/female pairs are shown in the Figure as red stars $(\mathrm{P}<0.05)$ 

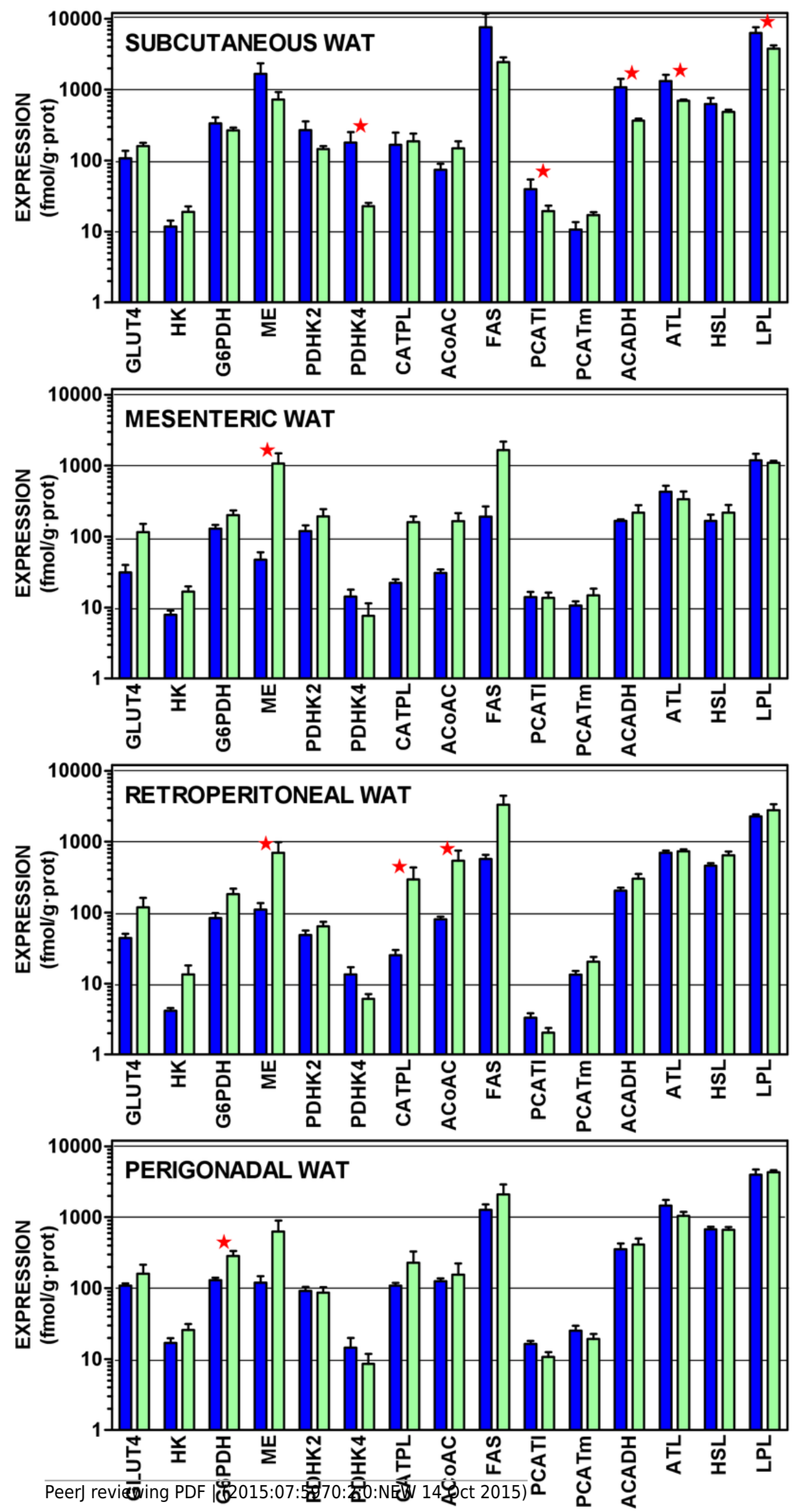